\title{
The Estimation of Lethal doses for Acyclovir, Insulin and Ondansetron on developing chick embryos
}

\author{
Pradeep Bokariya ${ }^{1}, \mathrm{BN}_{\text {Umarji }}{ }^{2}$ \\ 1 Research Scholar,KIMS, Karad 2 Professor \& Head, Dept of AnatomyKIMS, Karad
}

\begin{abstract}
There is paucity of data for lethal doses of insulin, ondansetron and acyclovir on developing chick embryo. The study was conducted to estimate the lethal doses for these drugs. Study also aims at observing Lowest published toxic concentration (TCLo), Lowest published lethal dose (LDLo), No Observable Adverse Effect Level (NOAEL), Lowest Observable Adverse Effect Level (LOAEL) for these drugs. Total of 132 eggs were taken for study which were divided into four groups. The number of survived eggs was noted for specific dose of each drug and on the basis of same lethal doses for each drug was evaluated. EPI software was used for statistical analysis. Cent percent mortality was seen in group injected with $2 \mathrm{mg}$ of ondansetron. The dose $5 I U(I n t e r n a t i o n a l ~ U n i t)$ of insulin was estimated as lethal dose and $2.5 \mathrm{mg}$ for acyclovir.
\end{abstract}

Keywords - lethal doses, Acyclovir, Ondansetron, Insulin

\section{INTRODUCTION}

The insulin \& ondansetron are widely used by pregnant women. Similarly intake of acyclovir is also not so uncommon among gravid ladies. There is dearth of published data as far as lethal doses of acyclovir and ondansetron related to developing chick embryo is concerned. So it is thought pertinent to conduct such study to estimate lethal doses for these drugs. Special stress was laid on estimation of median lethal doses for these drugs. Study also aims in estimating and observing other measures of toxicity for chick embryo as Lowest published toxic concentration (TCLo), Lowest published lethal dose (LDLo), No Observable Adverse Effect Level (NOAEL), Lowest Observable Adverse Effect Level (LOAEL). Many studies are being conducted so far using various drugs on developing chick embryo.

\section{METHODS}

Total of 132 eggs were used with prior permission from institutional ethics committee. These were divided into 4 major groups (one each for Insulin, Ondansetron, Acyclovir \& control). These major groups were further sub divided into minor groups of 6 eggs each on the basis of doses of drugs are concerned. The different doses of drugs were injected on $3^{\text {rd }}$ day of incubation. The pre-hatched eggs were dissected out on $19^{\text {th }}$ day to check mortality and other gross malformations if any. The dose range for insulin 1IU (International Unit) to $6 \mathrm{IU}$, for ondansetron $0.1 \mathrm{mg}$ to $2 \mathrm{mg}$ and for acyclovir it is $0.5 \mathrm{mg}$ to $3 \mathrm{mg}$. These dose ranges were evaluated by considering previous studies if available and on the experiment basis.

The embryos were also examined for any apparent congenital anomalies and absence or presence of limbs. Crown rump length was also measured for each survived embryo by passing a thread from root of beak along the back to the tip of coccyx and then measuring length of thread.

Data collected was fed in the computer and EPI Info software was used. Chi-square test was used for analyzing the data. The variable fed into the data analysis software was termed as 'survivability' where a value of ' 1 ' denoted alive embryos and a value of ' 2 ' denoted dead embryos.

\section{RESULTS}

Twenty out of twenty four embryos were survived in control group which supports ideal temperature and relative humidity used in experiment. The observations are shown in Table I \& Table II. Cent percent mortality was seen in group injected with $2 \mathrm{mg}$ of ondansetron. The dose $5 \mathrm{IU}$ of insulin was estimated as lethal dose for developing chick embryo. The observation for acyclovir is $2.5 \mathrm{mg}$ which matches with data already published. Twenty out of 24 controls embryo were survived and were compared with experimental groups. None case was observed with deformities in limbs. The comparison of CR length showed not significant when effect of insulin and ondansetron was analysed with control group whereas it was found to be significant when CR lengths of control and embryos treated with acyclovir was compared. In some dead embryos there was an area vasculosa, but in others, development seemed to have ceased before the migration of lateral mesoderm from the primitive streak. 
The estimation of lethal doses for acyclovir, insulin and ondansetron on developing chick embryos

\section{DISCUSSION}

Many such studies have been conducted on different animal models to ascertain lethal doses and to see teratogenic effect of those drugs. Though many studies are being conducted from time to time on chick embryo but data pertaining to drugs used in our experiment are scanty. The significance of these observations depends largely on our knowledge of the metabolism of the chick embryo between 24 and 48 hours of incubation and also on the interpretation of the many conflicting views on the mechanism of action of these drugs. In ovo experiments with the chick have been the most popular means of investigating the teratogenic action of insulin.

Landauer (1945), having determined that insulin will produce rumplessness when injected into the egg during the first 2 days, and micromelia and beak defects if injection is delayed until the 4 th or 5 th day, tested the effects of supplementing the insulin with intermediate carbohydrate metabolites.

There is a high level $(71 \%)$ of self medication amongst farms particularly with enrofloxacin and gentamycin. Medication without consultation with qualified veterinarians may result in the abuse and misuse of antibiotics with the attendant consequences of resistance and the occurrence of drug residues in poultry and poultry products. Although factors may include chick quality, disease, stress and nutrition, information on chick mortality on small-scale farms can be used for the training of farmers on brooding, disease control and sanitation. ${ }^{4}$

\section{CONCLUSION}

The data thus obtained will be of utmost utility because of paucity of references for further researchers. Detailed histological \& histochemical study will add more knowledge in discovering intricacies \& relevant use of these drugs. Moreover uses of these drugs are not so uncommon among gravid human women also. The study thus conducted warrants further more investigations on use of these drugs on human too.

\section{REFERENCES}

[1]. Kiran K, Yunus MK, Liaqat AM Effect of Ethanol Vapour Exposure on Survival of Chick Embryos Journal of the College of Physicians and Surgeons Pakistan 2009, 19 (3): 150-153

[2]. Chou CC, Jiang DD, Hung YP, Risk factors for cumulative mortality in broiler chicken flocks in the first week of life in Taiwan. Br. Poult. Sci., 2004; 45: 573-577.

[3]. Hamburger V, Hamilton H A series of normal stages in the development of the chick embryo. J. Morphol. 1951; 88:49-92

[4]. Muhammad M, Muhammad LU, Ambai AG, Mani AU A Survey of Early Chick Mortality on Small-Scale Poultry Farms in Jos, Central Nigeria International Journal of Poultry Science 2010; 9 (5): 446-449

[5]. Manner J, Kluth D. A chicken model to study the embryology of cloacal exstrophy. J Pediatr Surg 2003; 38:678-81.

[6]. Bujanda L, Garcia-Barcina M, Juan VG, Bidaurrazaga J, de Luco MF, Gutierrez-Stampa M, et al. Effect of resveratrol on alcohol-induced mortality and liver lesions in mice. BMC Gastroenterol 2006; 6:35.

[7]. Landauer W. Rumplessness of chicken embryos produced by the injection of insulin and other chemicals. J. exp. Zool. 1945; 98 , $65-77$. 
The estimation of lethal doses for acyclovir, insulin and ondansetron on developing chick embryos

Table 1: Showing the relation of quantity of drugs used and mortality caused by drugs. (Number of eggs in each group are 6)

\begin{tabular}{|l|l|l|l|l|l|}
\hline \multicolumn{2}{|l|}{ Ondansetron } & Insulin & Acyclovir \\
\hline Dose & Mortality & Dose & Mortality & Dose & Mortality \\
\hline $0.2 \mathrm{mg}$ & 5 Survived & $1 \mathrm{IU}$ & 6 Survived & $0.5 \mathrm{mg}$ & 6 Survived \\
\hline $0.4 \mathrm{mg}$ & 6 Survived & 2IU & 5 Survived & $1.0 \mathrm{mg}$ & 6 Survived \\
\hline $1.0 \mathrm{mg}$ & 4 survived & $3 \mathrm{IU}$ & 3 Survived & $1.5 \mathrm{mg}$ & 3 Survived \\
\hline $1.2 \mathrm{mg}$ & 3 Survived & $4 \mathrm{IU}$ & 3 Survived & $2 \mathrm{mg}$ & 2 Survived \\
\hline $1.6 \mathrm{mg}$ & 2 Survived & $5 \mathrm{IU}$ & All 6 Expired & $2.5 \mathrm{mg}$ & All 6 Expired \\
\hline $2.0 \mathrm{mg}$ & All 6 Expired & $6 \mathrm{IU}$ & All 6 Expired & $3 \mathrm{mg}$ & All 6 Expired \\
\hline
\end{tabular}

Table 2: The observations elucidated from the findings seen in present study with reference to previous similar studies.

\begin{tabular}{|c|c|c|c|}
\hline Parameter & Insulin & Ondansetron & Acyclovir \\
\hline Dose Range & $1 \mathrm{IU}$ to $6 \mathrm{IU}$ & $0.1 \mathrm{mg}$ to $2.0 \mathrm{mg}$ & $0.5 \mathrm{mg}-4 \mathrm{mg}$ \\
\hline \begin{tabular}{lcc|} 
No Observable & Adverse & Effect \\
Level (NOAEL) & & \\
\end{tabular} & $1 \mathrm{IU}$ & $0.4 \mathrm{mg}$ & $1.0 \mathrm{mg}$ \\
\hline $\begin{array}{l}\text { Lowest Observable Adverse Effect } \\
\text { Level (LOAEL) }\end{array}$ & $2 \mathrm{IU}$ & $1.0 \mathrm{mg}$ & $1.5 \mathrm{mg}$ \\
\hline Median Lethal Dose & $3 \mathrm{IU}$ & $1.2 \mathrm{mg}$ & $1.5 \mathrm{mg}$ \\
\hline Toxic Dose in present study & $4 \mathrm{IU}$ & $1.6 \mathrm{mg}$ & $2 \mathrm{mg}$ \\
\hline $\begin{array}{lcc}\begin{array}{l}\text { Lowest } \\
\text { concentration (TCLo) }\end{array} & \text { toxic } \\
\end{array}$ & NA & NA & $\mathbf{N A}$ \\
\hline Lethal dose in present study & $5 \mathrm{IU}$ & $2 \mathrm{mg}$ & $3 \mathrm{mg}$ \\
\hline $\begin{array}{lll}\begin{array}{l}\text { Lowest } \\
\text { dose (LDLo) }\end{array} & \text { published } & \text { lethal } \\
\end{array}$ & $4 \mathrm{IU}$ & $\mathbf{N A}$ & $\mathbf{N A}$ \\
\hline
\end{tabular}

